\title{
Neue Berufungen
}

Liebe Leserin, lieber Leser,

die Digitalisierung führt zu einem Wandel der Managementkultur und damit zu großen Veränderungen des Faktors Arbeit. Die Automobilindustrie wird künftig mehr tun, als nur Fahrzeuge zu bauen. Bei dieser Neuorientierung der Branche geht es immer stärker um das Ökosystem an Dienstleistungen, die rund um das Fahrzeug geboten werden.

Bei der Wende zum Auto der Zukunft sind gerade die IT- und Elektronikfachleute sehr gefragt. Zusätzlich wird der schrittweise Umstieg vom Verbrennungs- zum Elektromotor deutliche Auswirkungen auf die Arbeitsplätze haben. Neue Berufsbilder entstehen, für die oft neue Qualifikationen erforderlich sind. Gerade im Engineeringbereich verschmelzen Arbeitsbereiche stärker miteinander.

Die überall neu entstehenden Geschäftsbereiche bei OEMs und Start-ups bieten exzellente Chancen für Ingenieure mit IT-Kenntnissen - zum Beispiel als Data Scientist, einer Mischung aus Informatiker, Mathematiker und Ingenieur.

Hochschulen und Universitäten bemühen sich aktuell, dieser Nachfrage durch attraktive Neuausrichtungen von Studiengängen und -schwerpunkten gerecht $\mathrm{zu}$ werden. Wir stellen Angebote der RWTH Aachen University und der Universität Stuttgart stellvertretend im Heft vor.

Auch berufserfahrene Ingenieure sollten ihre Weiterbildung nicht aus den
Augen verlieren. Als Option für diese Zielgruppe schlägt die LVQ in diesem ATZextra eine Weiterqualifizierung in den Bereichen Arbeitsschutz oder Qualitätsmanagment vor. Auch der Ausbau von Managementskills zu einer Führungsposition bietet spannende Optionen in den reiferen Berufsjahren.

Mit dem Aufkommen agiler, datengetriebener Führungs- und Planungsmethoden wie zum Beispiel Scrum wird ein Projektleiter künftig auch um eine Erweiterung seines Qualifizierungsprofils um datenanalytische Fähigkeiten nicht herumkommen.

Wir wünschen Ihnen eine anregende Lektüre.

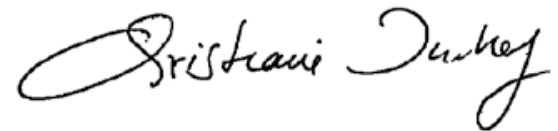

Christiane Imhof Redaktion ATZextra

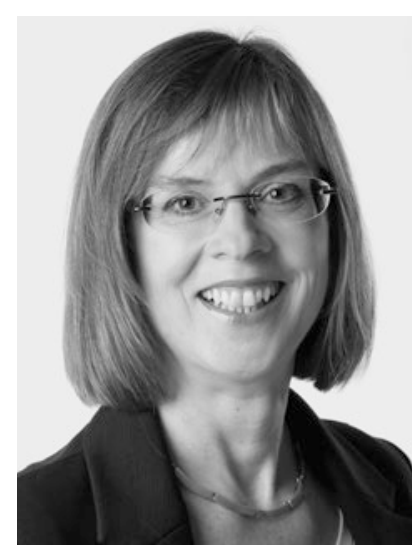

